\title{
Fluoropolymer Microstructure and Dynamics: Influence of Molecular Orientation Induced by Uniaxial Drawing
}

\author{
Daniel F. Miranda ${ }^{1}$, Chaoqing Yin ${ }^{1}$, Shihai Zhang ${ }^{2}$, James Runt ${ }^{*}$ \\ ${ }^{1}$ Department of Materials Science and Engineering, The Pennsylvania State University, \\ University Park, Pennsylvania, 16802 \\ ${ }^{2}$ PolyK Technologies, LLC, 2124 Old Gatesburg Road, State College, PA 16803 \\ "Corresponding author. Email address: runt@matse.psu.edu
}

Keywords: uniaxial drawing, polymer crystallization, dielectric spectroscopy

\begin{abstract}
Fluorinated semi-crystalline polymers are attractive for dielectric film applications due to their chemical inertness and high thermal stability. In the present investigation we explore the influence of orientation induced by uniaxial drawing on the crystalline microstructure and relaxation processes of poly(ethylene-tetrafluoroethylene) (ETFE), in order to ascertain how morphological control can benefit polymer dielectric design. When drawn below or near the $\mathrm{T}_{\mathrm{g}}$, the crystallinity of the drawn films is unchanged, and oriented amorphous structures and crystalline microfibrils form at high draw ratios. This orientation slows segmental relaxation, reflected by an increase in the dynamic $T_{g}$. When drawing above $T_{g}$, the films undergo straininduced crystallization at high draw ratios. For these films, an increase in dynamic $\mathrm{T}_{\mathrm{g}}$ is also observed, in addition to a second segmental relaxation process, appearing as a shoulder on the primary process. We propose that this represents a contribution from a rigid amorphous fraction, having slowed chain dynamics.
\end{abstract}




\section{Introduction}

Poly(ethylene-co-tetrafluoroethylene) (ETFE) is a melt-processible semi-crystalline copolymer, combining the processibility of polyethylene with the chemical inertness and high temperature resistance of poly(tetrafluoroethylene). ${ }^{1}$ ETFE has seen increasing use over the past few decades as linings or coatings due to its stability against chemical attack, and ETFE foils have been used for roofs and building claddings owing to their mechanical toughness and high chemical and UV resistance. ${ }^{1}$ ETFE is also used for applications such as electrical insulation and wiring owing to its excellent dielectric properties over a broad range of temperatures. ${ }^{1,2}$

These dielectric properties are also promising for use as the dielectric layer in power capacitors. Metallized polymer dielectric films have the unique capacity to self-heal, increasing the lifetime of the capacitor. ${ }^{3}$ Biaxially oriented polypropylene (BOPP) is the state of the art polymer dielectric due to its very low dissipation factor $(\tan \delta)$ and high breakdown strength, and industrial processes for producing high-quality polypropylene film are well established. ${ }^{4}$ However, its dielectric constant is low $(2.2 \text { at } 1 \mathrm{kHz})^{5}$, limiting the maximum achievable energy density. Much effort has been directed toward producing polymer dielectrics that provide higher energy density capacitors by increasing the dielectric constant through the use of polymer nanocomposites, ${ }^{6-8}$ multilayer films, ${ }^{9,10}$ and relaxor ferroelectric polymer films. ${ }^{5,11,12}$ These and other methods have been reviewed extensively. ${ }^{13-15}$ What has received less attention, however, is the low maximum operating of BOPP, $105^{\circ} \mathrm{C}$. This restricts the usage of BOPP-based capacitors to low temperature applications, while the need for high-temperature capacitor devices is increasing. ${ }^{16}$

ETFE has a high melting temperature $\left(\mathrm{T}_{\mathrm{m}}, 255-285^{\circ} \mathrm{C}\right),{ }^{10-12}$ well above the operation temperatures currently considered for power capacitors, and also has a very low dissipation 
factor $\left(\sim 0.001 \text { at } 22{ }^{\circ} \mathrm{C} \text { and } 1 \mathrm{kHz}\right)^{1}$. The majority of energy lost during capacitor operation is released as heat, and therefore low $\tan \delta$ is essential to preventing thermal runaway. In addition, the $\tan \delta$ of ETFE remains low at and after annealing at elevated temperatures. ${ }^{2}$

Film orientation and morphology is also an important factor for polymer dielectrics. Biaxial orientation of polypropylene has been found to greatly increase the breakdown strength of the polymer film, ${ }^{4}$ and orientation may provide benefits to other polymer dielectric films as well. Polymer orientation generated by uniaxial drawing has generally been found to induce further crystallization in semi-crystalline polymers ${ }^{20}$. It is well known that polymer crystallization suppresses the glass transition ${ }^{21}$ (and therefore decreased dielectric losses from this transition) and further crystallization induced by drawing may suppress it further.

There have been some prior studies on the effect of drawing and chain orientation on ETFE films. ${ }^{22-25}$ Films at high extension adopt an oriented herringbone-type arrangement of crystal lamellae. ${ }^{22,25}$ Film extension and orientation has also been suggested to induce formation of an extended-chain conformation. ${ }^{23}$ Biaxial orientation has also been investigated. ${ }^{24}$ However there has been no discussion on how the oriented lamellar morphology develops in ETFE as extension is increased, and how this affects the segmental dynamics. Many studies have been carried out to determine the unit cell structure of crystalline ETFE. Most reports infer an orthorhombic unit cell, ${ }^{23,26-29}$ although monoclinic ${ }^{22,30}$ and triclinic ${ }^{17}$ unit cells have also been proposed. It is also generally agreed that the unit cell consists of two alternating chains in a planar zigzag conformation, ${ }^{23,27,29}$ but cells containing four chains have also been proposed. ${ }^{26,30}$ A high temperature polymorph also exists, which conforms to a hexagonal unit cell. ${ }^{17,25,26,31}$

In this paper, the effects of orientation on polymer morphology, and its corresponding effect on the dielectric properties, were examined for ETFE films. The films were drawn at 
temperatures below, in the vicinity of, and above the $\mathrm{T}_{\mathrm{g}}\left(\sim 100{ }^{\circ} \mathrm{C}\right) .{ }^{19,23,31}$ The morphology varies incrementally with increasing film extension, and greatly with drawing temperature. These differing morphologies have a significant effect on the dielectric behavior of the films, with those stretched to high draw ratios at high temperature presenting the greatest changes.

\section{Experimental}

Materials. ETFE resin $\left(\right.$ Tefzel $^{\circledR}$ 200) was obtained from DuPont. Films were extruded from the resin using a 1 inch single screw extruder with a 6 inch flex lip film die, at a temperature of $300{ }^{\circ} \mathrm{C}$. It was determined that the extrusion imparted substantial preferred orientation to the film (Supplementary Data, Figure S1a and S1b), which would complicate the findings of later experiments. Therefore, prior to any further experiments, the extruded film was annealed at $140{ }^{\circ} \mathrm{C}$ for $3 \mathrm{hrs}$. This treatment was shown to nearly erase the history imparted by extrusion (Supplementary Data, Figure S1c). Samples for drawing were then cut from the annealed film to have an approximate gage area of $2.5 \times 3.5 \mathrm{~cm}$, and were marked with horizontal and vertical gage lines using a square grid template, each line separated by $0.5 \mathrm{~cm}$ (see for example, Figure S2).

Drawing of the prepared films was carried out at $50{ }^{\circ} \mathrm{C}, 100{ }^{\circ} \mathrm{C}$, and $140{ }^{\circ} \mathrm{C}$, using an Instron Model 5866 equipped with an air oven and pneumatic grips. A strain rate of $10 \mathrm{~mm} / \mathrm{min}$ was used for all samples.

Characterization. Differential scanning calorimetry (DSC) was used to estimate the degree of crystallinity under different stretching conditions. For each film, circular samples were obtained using a hole puncher, with each sample weighing between 2 and $10 \mathrm{mg}$. The samples were packed into standard aluminum DSC pans, and heated from $40{ }^{\circ} \mathrm{C}$ to $300{ }^{\circ} \mathrm{C}$ at a rate of 5 
${ }^{\circ} \mathrm{C} / \mathrm{min}$. A TA Instruments model Q2000 was used for all the DSC experiments. Crystallinities were determined by normalizing the measured heats of fusion to the reported heat of fusion for the $100 \%$ crystalline polymer $(113 \mathrm{~J} / \mathrm{g}) .^{32}$

Small- and wide-angle X-ray scattering (SAXS and WAXS) were used to characterize the morphology of the deformed films. The SAXS data were collected using a Molecular Metrology instrument with a $\mathrm{Cu} \mathrm{K}_{\alpha}$ radiation source $(\lambda=1.54 \AA)$ at $45 \mathrm{kV}$ and $66 \mathrm{~mA}$, using a twodimensional multiwire detector with a sample-to-detector distance of $1.5 \mathrm{~m}$. 1-D integrated data were obtained averaging over $0.0021 \leq \mathrm{q}\left(\AA^{-1}\right) \leq 0.2$ and $0^{\circ} \leq \chi \leq 360^{\circ}$ ( $\chi$ being the azimuthal angle). WAXS 1-D integrated data were collected on a Rigaku DMAX/rapid micro diffractometer in transmission mode, using a copper point-focused source $(\lambda=0.154 \mathrm{~nm})$ at 50 $\mathrm{kV}$ and $40 \mathrm{~mA}$. WAXS 2-D images were obtained using a Rigaku Microfocus Micromax 007HF in transmission mode, equipped with a Molybdenum point-focused source $(\lambda=0.071 \mathrm{~nm})$. A typical image acquisition time was $20 \mathrm{~s}$. The diffraction patterns were analyzed using the software GADDS.

Dynamic mechanical analysis (DMA) measurements were carried out on a TA Instruments model DMA Q800, equipped with an NPC cooler using liquid nitrogen. Samples were prepared as rectangular strips and mounted in the standard tension clamp kit provided by TA. A temperature sweep was carried out from $-150{ }^{\circ} \mathrm{C}$ to $200{ }^{\circ} \mathrm{C}$, with a heating rate of 3 ${ }^{\circ} \mathrm{C} / \mathrm{min}$, at a constant strain of $0.25 \%$ and frequency of $1 \mathrm{~Hz}$. Data was collected on heating.

Dielectric relaxation spectroscopy (DRS) measurements were performed using a Novocontrol GmbH Concept 40 broadband dielectric spectrometer. Frequency sweeps were performed isothermally from $0.1 \mathrm{~Hz}$ to $10 \mathrm{MHz}$ in the temperature range from $-150{ }^{\circ} \mathrm{C}$ to 200 ${ }^{\circ} \mathrm{C}$, with data collected on heating. The analyzer was supported by a Quatro temperature 
controller providing temperature stability better than $0.1^{\circ} \mathrm{C}$. The samples were prepared between two brass electrodes as a parallel plate capacitor. The applied voltage for each experiment was 1 V. Several functions were used to model and fit the dielectric data. Fits to the dielectric functions were carried out using the OriginPro 8.5 software. The Havriliak-Nagami equation was used to fit relaxations in the frequency domain:

$$
\varepsilon_{H N}^{*}=\frac{\Delta \varepsilon}{\left[1+\left(\mathrm{i} f / f_{H N}\right)^{a}\right]^{b}}
$$

where $\Delta \varepsilon$ is the relaxation strength, $a$ and $b$ are shape parameters, and $f_{H N}$ is a characteristic frequency, related to the frequency of maximum $\operatorname{loss} f_{\max }$ by:

$$
f_{\max }=f_{H N}\left(\sin \frac{a \pi}{2+2 b}\right)^{1 / a}\left(\sin \frac{a b \pi}{2+2 b}\right)^{-1 / a}
$$

There is also a measureable ion conductivity, likely corresponding to impurity ions which become mobile above the $\alpha$ transition. The temperature dependence of the DC conductivities were fitted as a first approximation to a VFT function:

$$
\sigma=\sigma_{\infty} e^{-B / T-T_{0}}
$$

where $\sigma_{\infty}$ is the conductivity as $\mathrm{T} \rightarrow \infty, B$ is a constant, and $T_{0}$ the Vogel temperature, at which conductivity goes to zero. 


\section{Results and Discussion}

\section{Drawing}

ETFE films were drawn at $50{ }^{\circ} \mathrm{C}, 100{ }^{\circ} \mathrm{C}$, and $140{ }^{\circ} \mathrm{C}$, such that the films were stretched below, in the vicinity of, and above the reported $\mathrm{T}_{\mathrm{g}}$ of ETFE, respectively $\left(\sim 100{ }^{\circ} \mathrm{C}\right)^{19,23,31}$. Using the gage marks on the drawn films, the extension ratio $(\lambda)$ could be accurately determined for each drawing condition (Table I).

Table I. Measured extension of film gage sections.

\begin{tabular}{|cc|}
\hline $\begin{array}{c}\text { Measured } \\
\text { Draw Ratio }\end{array}$ & Sample \\
\hline 1.7 & $50 \mathrm{C}-1.7 \lambda$ \\
2.2 & $50 \mathrm{C}-2.2 \lambda$ \\
2.7 & $50 \mathrm{C}-2.7 \lambda$ \\
3.0 & $50 \mathrm{C}-3.0 \lambda$ \\
\hline 2.0 & $100 \mathrm{C}-2.0 \lambda$ \\
2.8 & $100 \mathrm{C}-2.8 \lambda$ \\
3.3 & $100 \mathrm{C}-3.3 \lambda$ \\
3.7 & $100 \mathrm{C}-3.7 \lambda$ \\
4.3 & $100 \mathrm{C}-4.3 \lambda$ \\
\hline 1.7 & $140 \mathrm{C}-1.7 \lambda$ \\
2.7 & $140 \mathrm{C}-2.7 \lambda$ \\
3.5 & $140 \mathrm{C}-3.5 \lambda$ \\
4.2 & $140 \mathrm{C}-4.2 \lambda$ \\
4.8 & $140 \mathrm{C}-4.8 \lambda$ \\
\hline
\end{tabular}

Engineering stress-strain curves of the films drawn at each temperature are plotted in Figure 1. The plots all show an elastic response at very low apparent strains, after which there is a yield point followed by plastic deformation and necking, characterized by a region where stress is nearly independent of strain. For films drawn at $50{ }^{\circ} \mathrm{C}$ and $100{ }^{\circ} \mathrm{C}$, an additional region is observed where the stress begins to again increase slightly at strains greater than $3.0-4.0$, 
representing strain-hardening and possibly strain-induced crystallization, although straincrystallization at these temperatures is later ruled out by the DSC measurements. Films drawn at $140{ }^{\circ} \mathrm{C}$ also show a slight upturn at higher strains, although it is much more subtle. DSC measurements do indicate some strain-induced crystallization for stretching at $140{ }^{\circ} \mathrm{C}$, which is consistent with the upturn.

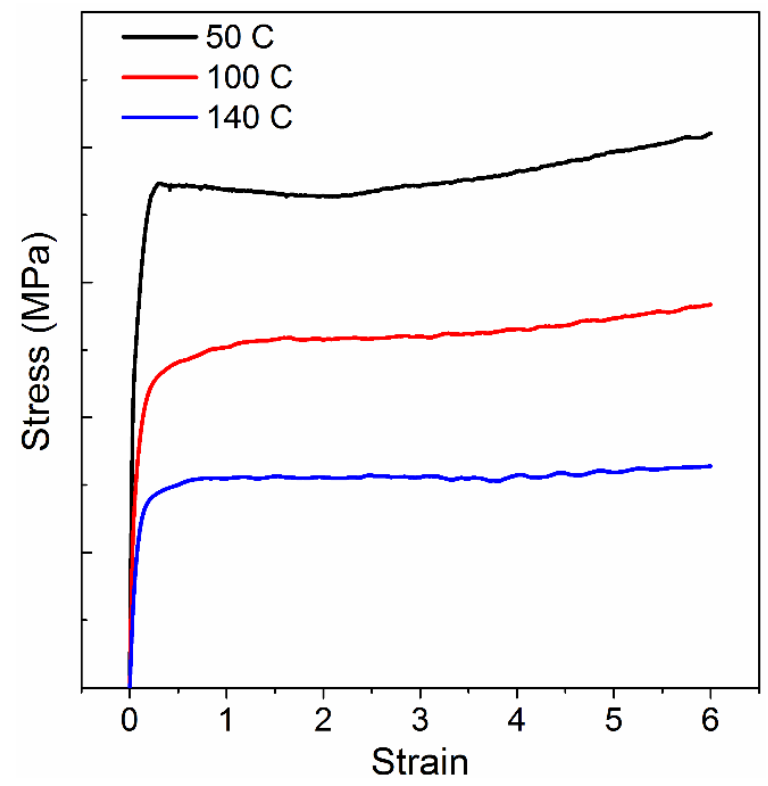

Figure 1. Stress-strain curves for drawn films at varying temperatures. Strain in this figure is derived from the extension programmed into the Instron, not from that measured from film gage marks (an extensometer was not used, and thus the instantaneous length and cross-sectional area were not available). The curves terminate at the end of the programmed extension, not failure.

\section{Crystallinity}

Heats of fusion $\left(\Delta \mathrm{H}_{\mathrm{m}}\right)$ measured by DSC were used to evaluate potential changes in the crystallinity of the stretched and unstretched films. The crystallinity of each film condition is summarized in Figure 2 below (details and endotherms in the Supplementary Data section, Table $\mathrm{S} 1$ and Figure S3). A prominent melting endotherm is seen at temperatures greater than $250{ }^{\circ} \mathrm{C}$, 
with peak temperatures between $265^{\circ} \mathrm{C}$ and $267{ }^{\circ} \mathrm{C}$ for all film conditions. The crystallinity of the films stretched at $50{ }^{\circ} \mathrm{C}$ and $100{ }^{\circ} \mathrm{C}$ at all stretching conditions are between $35-40 \%$, varying very little compared to the unstrained film (37\%). Therefore, the upturn for these temperatures seen at high extension in the stress vs. strain plots (Figure 1) does not represent any substantial degree of induced crystallization, and the observed strain-hardening arises from chain orientation. ${ }^{33,34}$ For films stretched at $140{ }^{\circ} \mathrm{C}$ however there is a substantial increase in crystallinity with extension, indicating strain-induced crystallization does occur at this temperature. At temperatures below the $\mathrm{T}_{\mathrm{g}}$, amorphous segmental mobility is too slow to permit chain folding of amorphous chains into crystals whereas above the $T_{\mathrm{g}}$ chain mobility is sufficient to allow the formation of new crystals. Strain-crystallization might be expected to produce a strong strain-hardening effect, however only a weak upturn is observed in figure 1. Most likely, the amorphous tie-chains are relaxed much more easily when drawing above $\mathrm{T}_{\mathrm{g}}$, which diminishes resistance to plastic flow, and thus the strain-hardening effect is less noticeable.

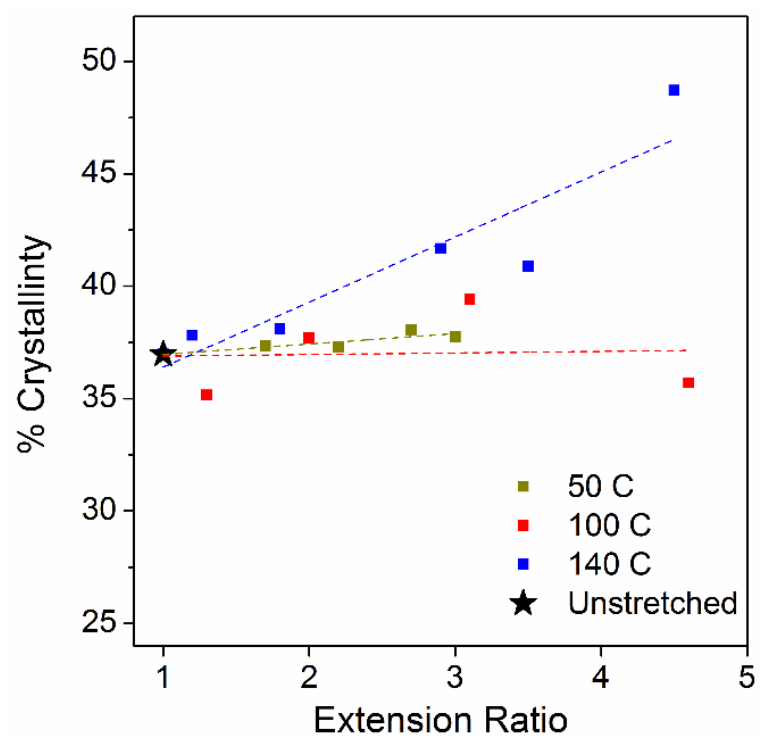


Figure 2. Summary of crystallinities at all film conditions. The dotted lines serve to guide the eyes. Uncertainties in measured heats of fusion are approximately +- $3 \mathrm{~J} / \mathrm{g}$ (approx. +- $2.6 \%$ Crystallinity).

\section{Morphology}

WAXS and SAXS measurements were used to evaluate the microstructural changes resulting from the deformation of the ETFE films. Figure 3 displays WAXS and SAXS patterns for all stretched films. For the undeformed film, both SAXS and WAXS show ring-like, isotropic scattering patterns, corresponding to an unoriented morphology. Upon stretching to even the lowest extensions, the scattering patterns change to reflect anisotropic morphologies - the WAXS patterns narrow into arcs centered on the equator and meridian, and SAXS patterns develop equatorial streaks and arcs on the equator.

\section{Morphology - Wide Angle X-ray Scattering}

The WAXS patterns for the unstretched and stretched films, regardless of the stretching temperatures, show two diffraction rings at approximately $2 \theta=19.5^{\circ}$ and $40^{\circ}$, corresponding to the (120) and (002) planes of the orthorhombic unit cell, respectively. ${ }^{28}$ There is also a small shoulder near $2 \theta=23^{\circ}$, arising from the (200) planes $^{28}$ (1-D scattering plots show this more clearly, Figure 4). The peak near $19.5^{\circ}$ (d-spacing $4.5 \AA$ ) can also have contributions from the (100) of a pseudo-hexagonal unit cell. The ETFE unit cell has a well-known temperature dependence, with a low temperature orthorhombic phase and high temperature hexagonal phase. $^{31}$ The reflection from the (100) plane of the hexagonal unit cell is at $\sim 19.0^{\circ}$ (d-spacing 
$4.7 \AA$ ), and co-exists as a pseudo-phase with the orthorhombic phase at temperatures from approximately $0-100{ }^{\circ} \mathrm{C} .^{31}$

With increasing extension, the scattering rings narrow into arcs as the films adopt a preferred orientation. The higher angle arc representing the (002) plane is normal to the stretching direction, signifying the polymer crystal $c$-axis aligns with the stretching direction. The arcs appear the sharpest and most intense for films stretched at $140{ }^{\circ} \mathrm{C}$, indicating the greatest orientation is achieved at this stretching temperature.
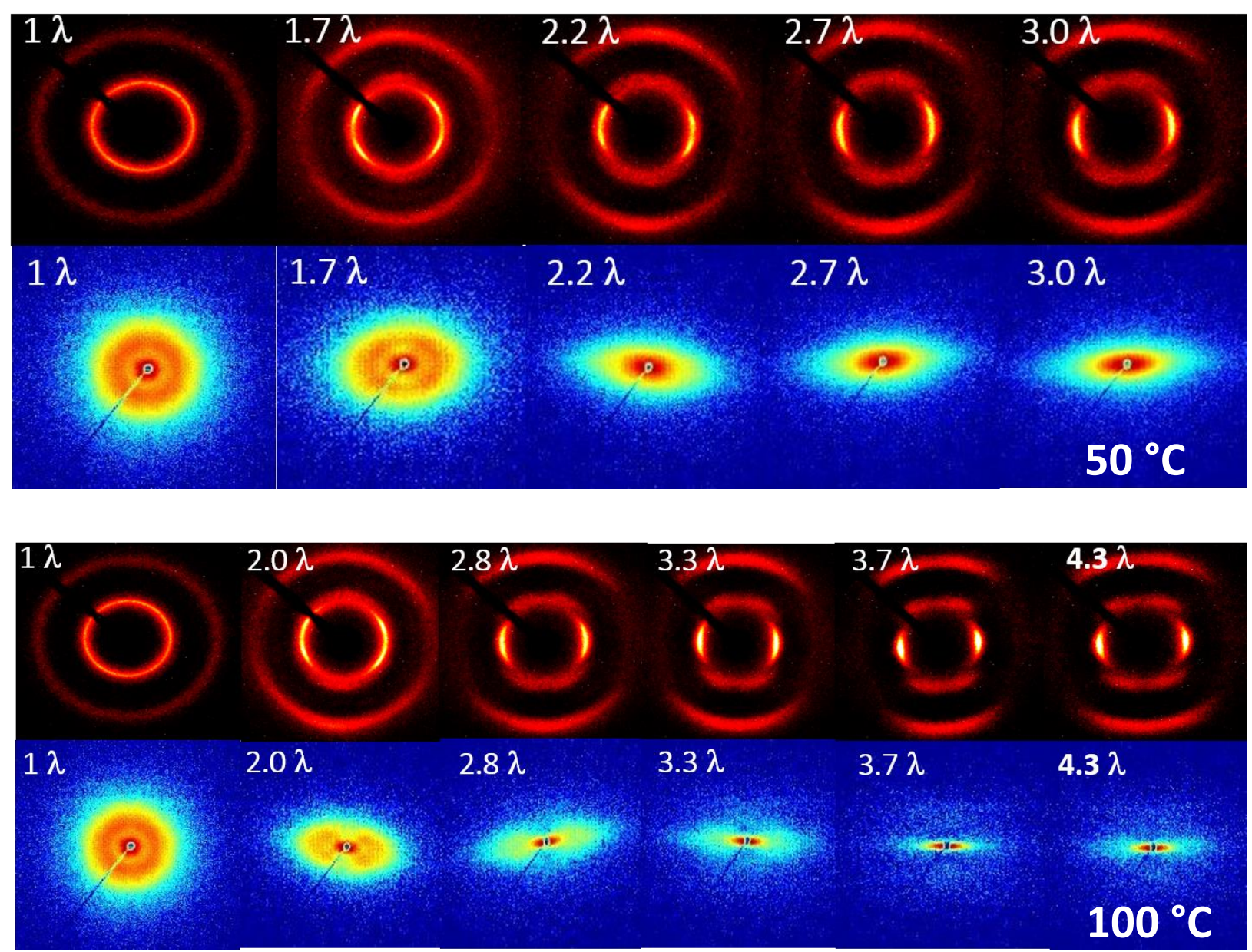


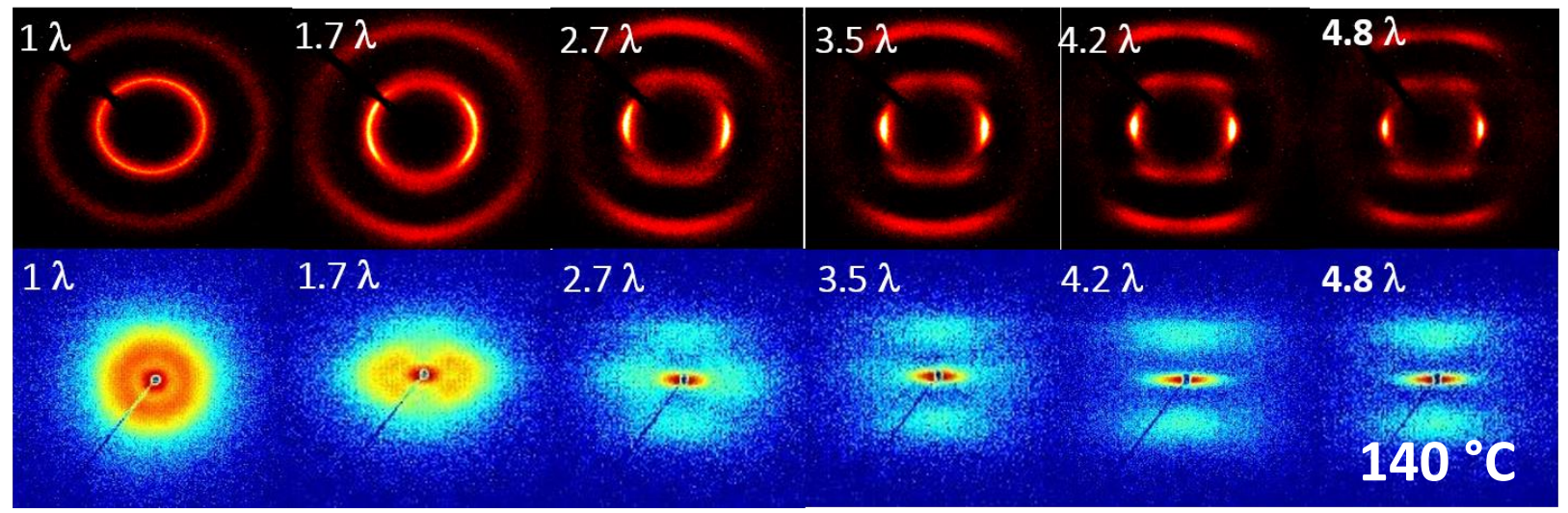

Figure 3. WAXS and SAXS two-dimensional patterns collected for all draw ratios investigated. The stretching direction is along the vertical axis of the figures.

Integrating the scattering patterns yields 1-D plots of intensity vs $2 \theta$ (Figure 4). At all stretching temperatures, the peak at $\sim 19.5^{\circ}$ becomes much broader compared to the unstretched film, and the shoulder near $23^{\circ}$ becomes more prominent in comparison. This may indicate that stretching in some way favors the orthorhombic phase. Figure $4 \mathrm{~d}$ shows the full width at half maximum (FWHM) of the combined (120) + (100) (orthorhombic and pseudo-hexagonal) peak, as well as the $\mathrm{d}$-spacing, derived from the angle $2 \theta$ corresponding to the maximum intensity. The FWHM increases sharply for the stretched films compared to the unstretched film, indicating increased coexistence of the orthorhombic and pseudo-hexagonal phases. The d-spacing of the $\sim 19.5^{\circ}$ peak also increases compared to the unstretched film, and as the (120) orthorhombic planes have a slightly larger period than the (100) hexagonal planes, the increase in the d-spacing further reinforces that stretching favors the orthorhombic phase. It is possible that increased orientation restricts the local motions associated with the gradual phase change to pseudohexagonal. ${ }^{31}$ Therefore, at the temperature of the WAXS experiments (ambient), a smaller fraction of the pseudo-hexagonal phase exists in the stretched films compared to the unstretched. 
From Figure $4 \mathrm{~d}$, it also appears that for films drawn at $140{ }^{\circ} \mathrm{C}$, while initially less favored at lower extension, the pseudo-hexagonal phase becomes increasingly favored at high extension. The FWHM reaches a maximum at $3.5 \lambda$, decreasing with further extension. The period also decreases at greater than $3.5 \lambda$, although this is within the approximate error. Since the straininduced crystals are forming at a temperature $\left(140{ }^{\circ} \mathrm{C}\right)$ where there is no remaining trace of the orthorhombic phase, ${ }^{31}$ the new crystals must nucleate with hexagonal unit cell structures, and therefore a greater proportion of the hexagonal phase is present when the WAXS experiments are performed at ambient temperature. However, this interpretation cannot explain why the period also reaches a maximum for films drawn at $100{ }^{\circ} \mathrm{C}$, where strain-induced crystallinity is not apparent (although the FWHM did not reach a maximum for these films.
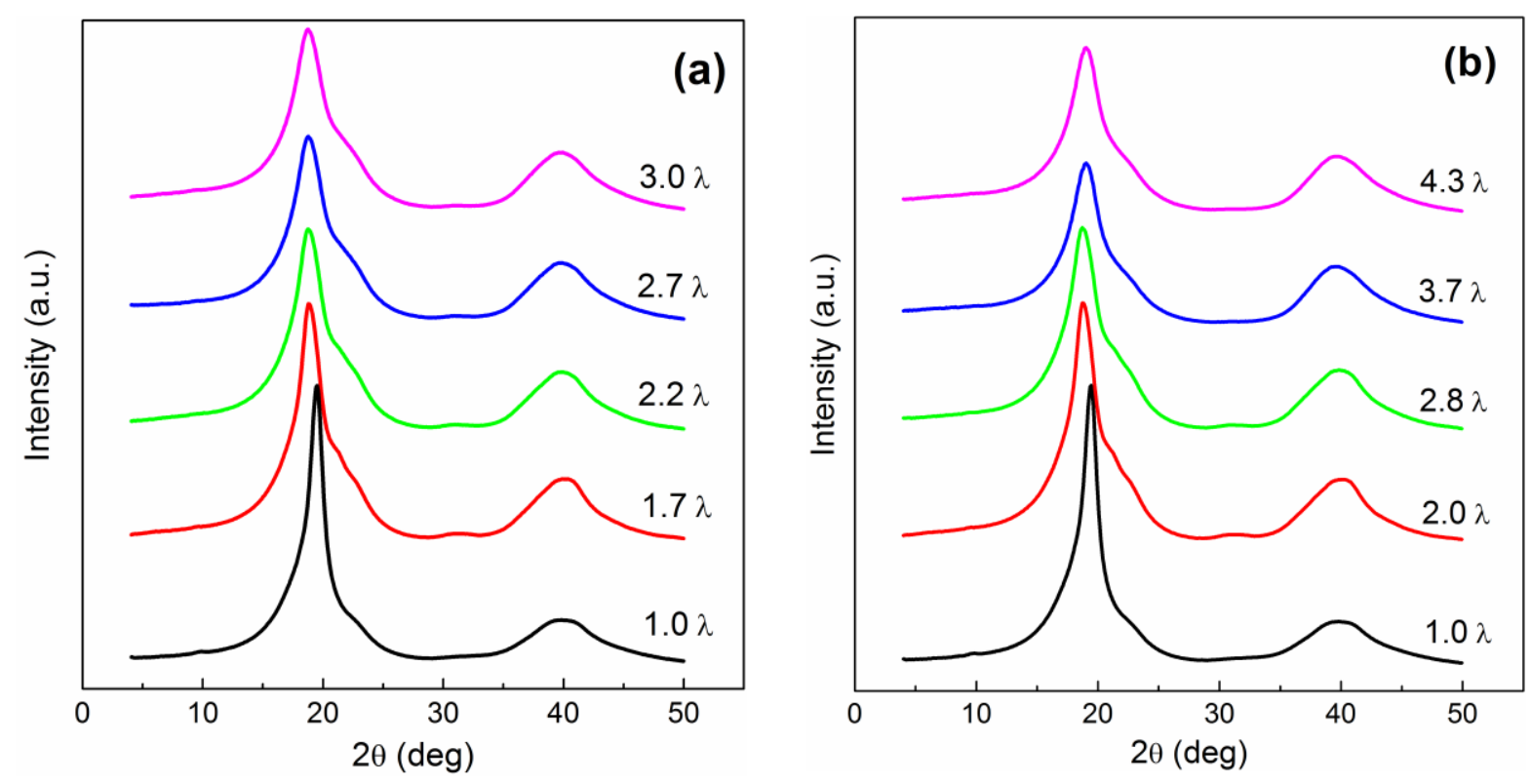

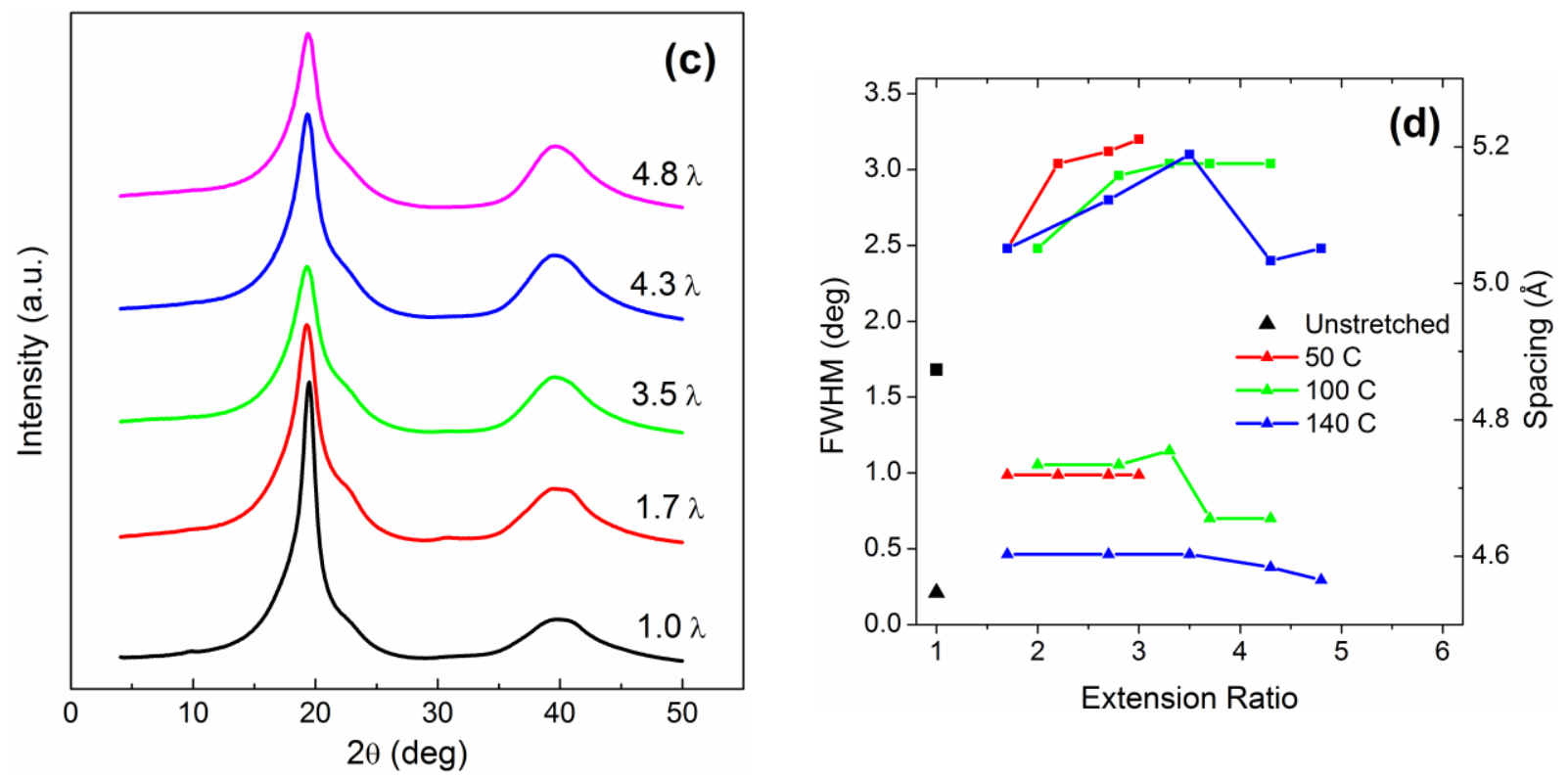

Figure 4. 1-D WAXS profiles of films stretched at (a) $50{ }^{\circ} \mathrm{C}$, (b) $100{ }^{\circ} \mathrm{C}$ and (c) $140{ }^{\circ} \mathrm{C}$ (plots offset for clarity), and (d) FWHM (square symbols, left axis, error 0.2 ) and d-spacing (triangle symbols, right axis, error $0.05 \AA$ ) for the combined $(120)+(100)$ peak at every stretching condition.

\section{Morphology - Small angle X-ray Scattering}

The SAXS patterns show extensive changes in the lamellar microstructure on stretching, with differing behaviors at each draw temperature. The undeformed sample shows an isotropic ring typical of a semi-crystalline lamellar structure, with a long period of $22.4 \mathrm{~nm}$. For all stretching temperatures, the isotropic pattern is disrupted at even the lowest extensions, although the resulting scattering patterns vary considerably depending on the stretching temperature.

Samples drawn at $50{ }^{\circ} \mathrm{C}$ to low extensions $(\lambda<2)$ adopt a pattern consisting of symmetrical arcs situated on the equator. Scattering intensity centered on the equator arises from crystal lamellae with their normal direction perpendicular to the stretching direction (i.e. oriented 
against), and intensity on the meridian corresponds to lamellae oriented with their normal parallel to the stretching direction (oriented with). The loss of intensity on the meridian (compared to the isotropic scattering pattern for the unstretched film) indicates that the scattering contrast from crystals having the corresponding orientation is significantly reduced. Since the chain-axis is aligned with the draw direction for this orientation, the amorphous segments between the lamellae will extend and orient along the draw direction, forming what has been described as an oriented mesophase. ${ }^{35-38}$ The mesophase will have a density approaching that of the lamellar regions, thus greatly diminishing X-ray scattering contrast. ${ }^{20,39}$

Further deformation $(\geq 2.2 \lambda)$ results in the disappearance of the equatorial arcs as well, and a loss of all scattering contrast in the SAXS q-range (Figure 5a). At these greater extensions, chain pullout and lamellar fragmentation may be occurring, disrupting the registry required for
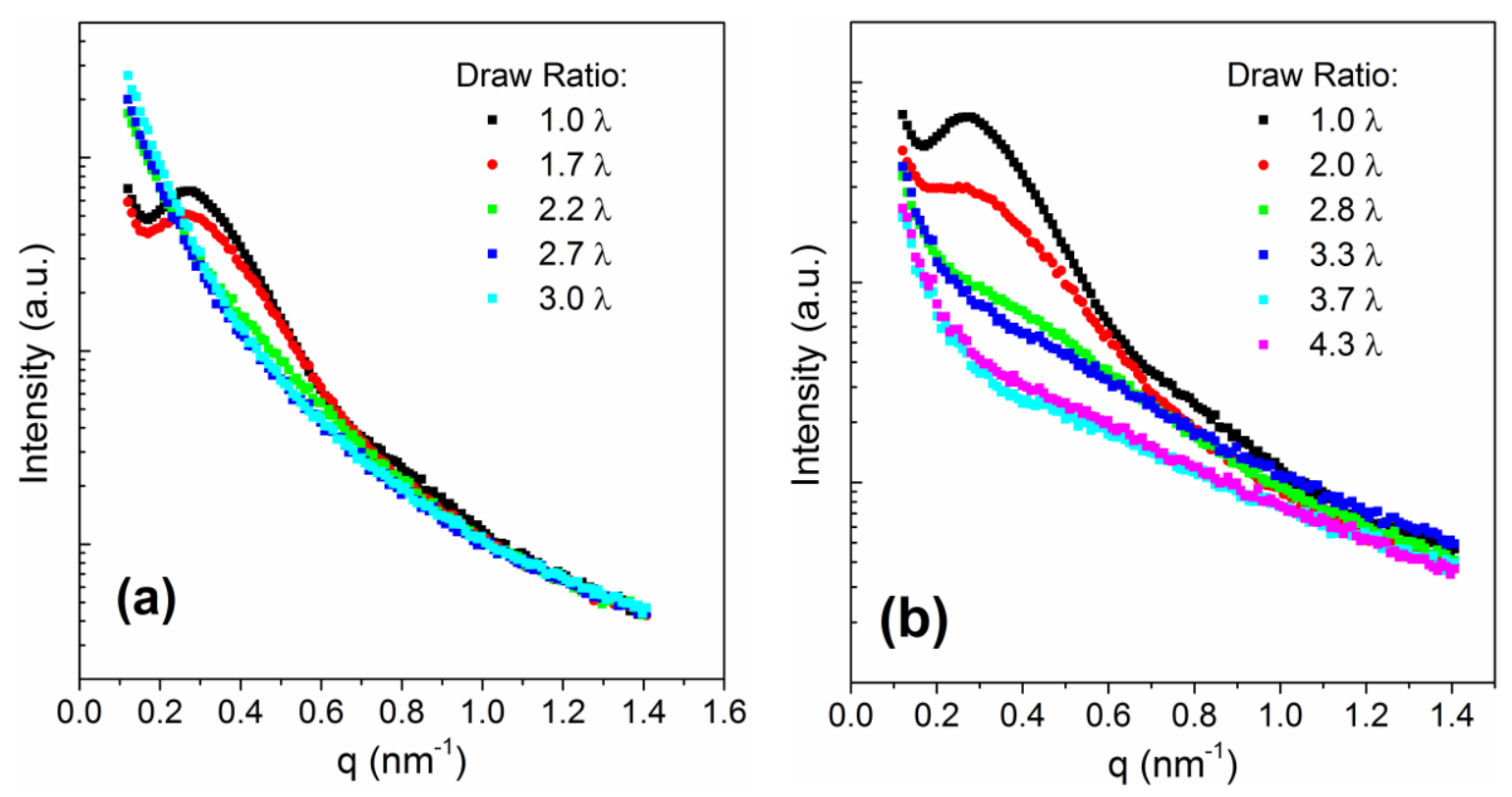


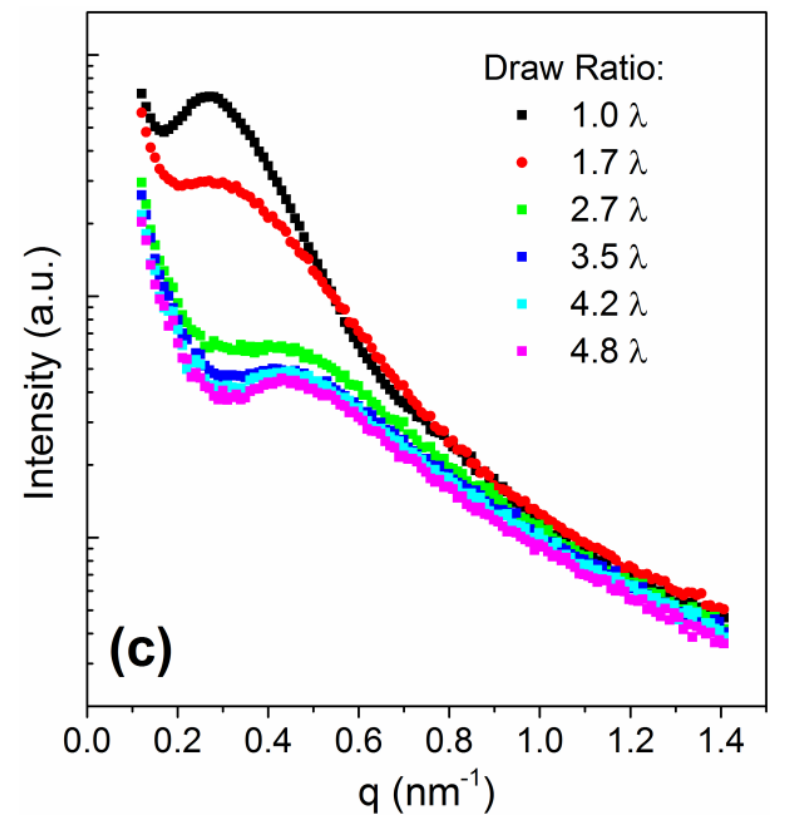

Figure 5. 1-D SAXS profiles of films stretched at (a) $50{ }^{\circ} \mathrm{C}$, (b) $100{ }^{\circ} \mathrm{C}$ and (c) $140{ }^{\circ} \mathrm{C}$.

X-ray contrast in the SAXS q-range and leading to the loss of intensity. Pullout may be followed by reformation into extended chain crystals; however in such a case, an increase in the melting point is expected due to the decreased entropy. ${ }^{40}$ Here, the melting point had no variance with stretching conditions (melting points for all between $265.7^{\circ} \mathrm{C}$ and $267.1^{\circ} \mathrm{C}$ ), so it is more likely that individual fragments form retaining a folded state. Also with higher extension, these fragments must have aligned with the draw direction, as the WAXS results (Figure 3a) show the unit cell chain axis (c-axis) becoming parallel with the draw direction.

Crystals with lamellar orientation between the two extremes (aligned with or against the draw direction) will likely re-orient to one or the other. Those lamellae orienting with the draw direction will develop oriented mesophases, and those oriented against will be destroyed as the draw ratio increases. 
Also at $\lambda \geq 2.2$, the scattering pattern includes an elliptical streak extending along the equator and centered on the beamstop. This phenomenon has been observed on many occasions for uniaxially drawn polyethylene and polypropylene films ${ }^{20,41-44}$ and for some ETFE films, ${ }^{22}$ and has been assigned either to the presence of micro-fibrillar polymer crystal formation consisting of aligned lamellar fragments, microvoids, or a combination of these features. Here, the strong scattering intensity suggests this streaking represents extensive microvoid formation, due to the large scattering contrast between the polymer and air. ${ }^{20}$ The microvoids likely arise from gaps between fibrils, with the films unable to close these gaps due to the limited chain mobility below $\mathrm{T}_{\mathrm{g}}$. The proposed morphology for films stretched at $50{ }^{\circ} \mathrm{C}$ is sketched in Figure 6. Therefore, for the highest draw ratio achieved for stretching below the $T_{g}$, the resulting morphology consists of lamellae primarily oriented with the draw direction having oriented mesophases between them, and microfibrils/microvoids formed by the destruction of lamellae oriented against the draw direction.

Draw

Direction

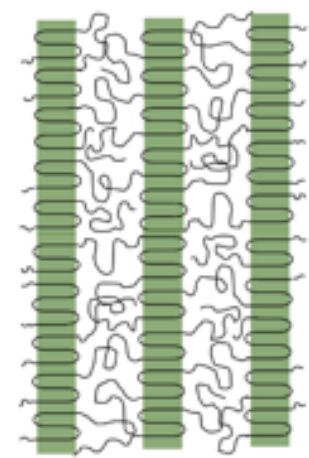

(a)

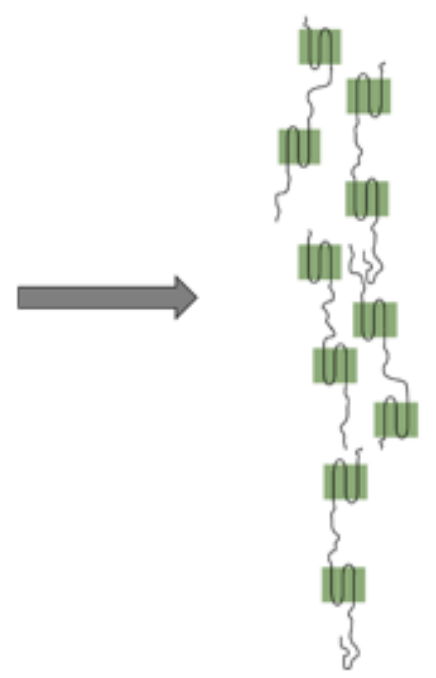

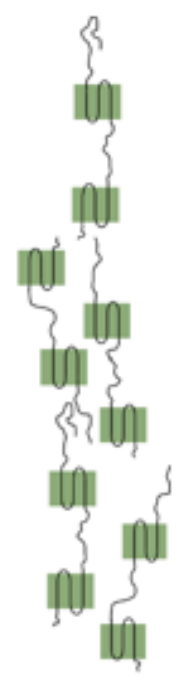




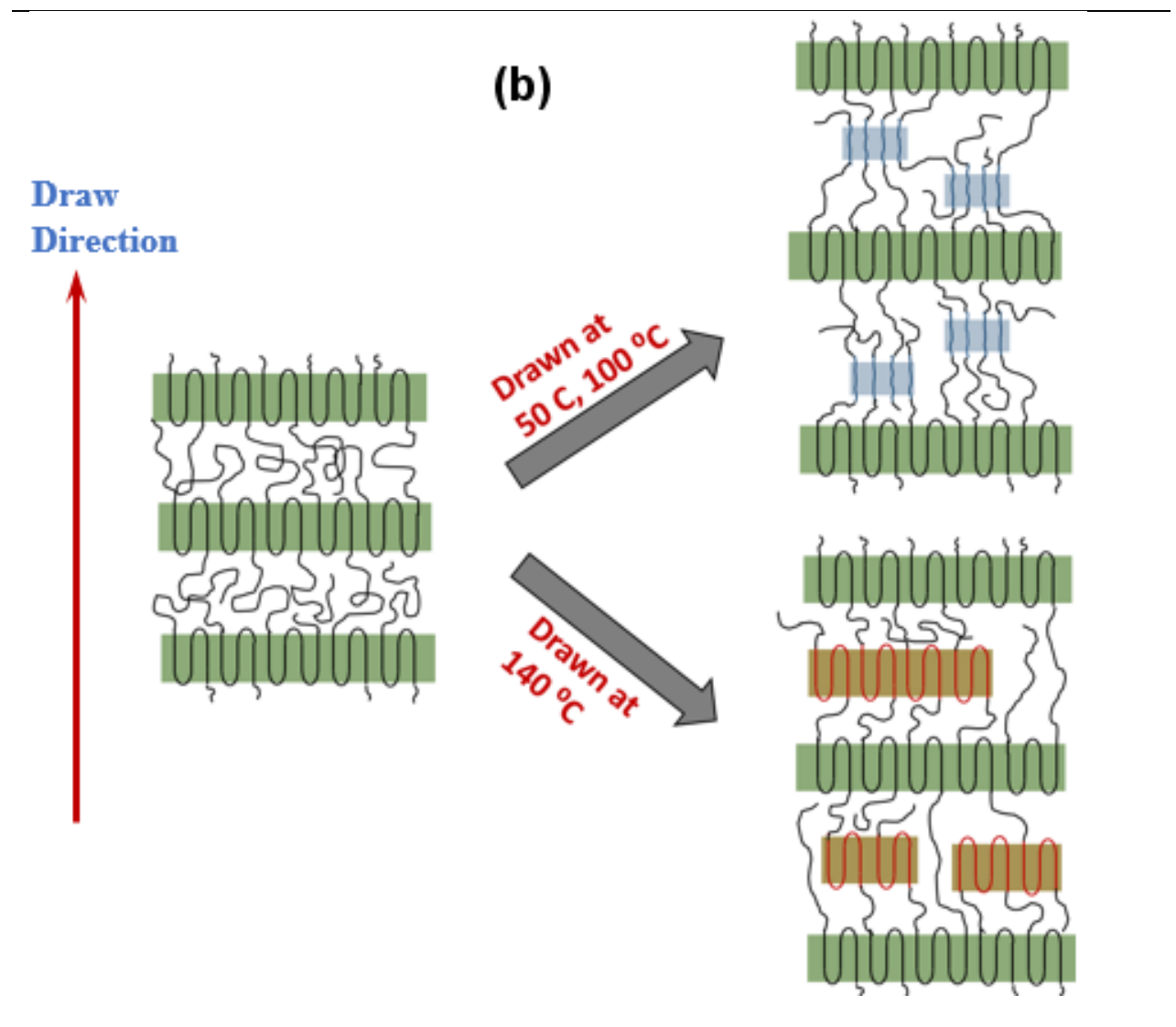

Figure 6. Illustrations of morphological changes for lamellae having their normal oriented (a) perpendicular and (b) parallel to the draw direction. Regions highlighted in blue are the oriented mesophase, and regions of red chains highlighted in brown are strain-induced crystals.

SAXS patterns of films stretched at $100{ }^{\circ} \mathrm{C}$ also divided into two equatorial arcs at low extension, similarly to those drawn at $50{ }^{\circ} \mathrm{C}$. These arcs also disappear with increasing draw ratio and all SAXS contrast is lost except at very low q near the beamstop on the equator (Figure $5 \mathrm{~b}$ ). However, these streaks appear less intense compared with the films stretched at the lower temperature of $50{ }^{\circ} \mathrm{C}$. Therefore, this scattering most likely arises primarily from microfibrils of oriented crystal fragments extending in the drawing direction, with microvoid formation being 
either minor or absent. At drawing temperatures near $\mathrm{T}_{\mathrm{g}}$, a combination of lamellae oriented with the draw direction, oriented mesophases, and microfibrils form at high extension.

Lastly, SAXS patterns for films stretched at $140{ }^{\circ} \mathrm{C}$ also show two opposing equatorial arcs, up to an extension of $1.7 \lambda$. However, as the extension ratio increases, a bar-like structure appears centered on the meridian, meaning the lamellae normal is strongly oriented in the draw direction. From the 1-D SAXS (Figure 5c), it is seen that this scattering arises from a structure having a smaller long period than the original crystals (14.3 nm compared to $22.4 \mathrm{~nm}$ ). At the highest draw ratio, the only remaining scattering intensity is from the intense streaks on the equator at low q, assigned to scattering from oriented microfibrils, and from the bar-like features on the meridian. These bars arise from strain-induced crystallization, identified by the DSC experiments (Figure 2), forming from oriented amorphous material in between the original crystal lamellae. Similar scattering features, having a smaller period than the starting crystals,

have been assigned to strain-induced crystals in other instances as well. ${ }^{20,43}$ These features do not form for films drawn below the $\mathrm{T}_{\mathrm{g}}$, and rather form oriented mesophases instead. This difference is illustrated in Figure $6 \mathrm{~b}$. Therefore, after drawing to high extension at temperatures above $\mathrm{T}_{\mathrm{g}}$, the morphology consists of microfibrils and strain-induced crystals in between original crystal lamellae, both strongly oriented with the draw direction.

\section{Mechanical and Dielectric Relaxations}

Dynamic mechanical analysis (DMA) was employed to measure the mechanical storage (E') and loss (E') moduli of the unstretched and stretched films at $140{ }^{\circ} \mathrm{C}$ (Figure 7). Four relaxations were observed for the unstretched film, referred to as $\gamma, \beta, \beta_{2}$, and $\alpha$ in order of increasing temperature. A similar profile above room temperature was observed for ETFE in 
prior work, ${ }^{31}$ and is used to assist in identifying the relaxations herein. The $\gamma$-process has been assigned to local relaxations in the glassy state involving torsional motions of the chains, and the $\alpha$-process with the dynamic glass transition (onset of segmental motion). The $\beta_{2}$-process has been proposed to arise from the gradual transition from the low temperature orthorhombic isomorph to the high temperature hexagonal form, ${ }^{31}$ and may also correspond to enhanced rotational/librational motion which allows the transition. ${ }^{17}$ The $\beta$-process has not been assigned, but it precedes the start of the transition to the hexagonal form, and may be related.

Upon stretching to an extension ratio of $4.5 \lambda$, the $\gamma$-process shifts to slightly higher temperature (from $-112{ }^{\circ} \mathrm{C}$ to $-108{ }^{\circ} \mathrm{C}$ ). This is not unexpected, as a local process should not be strongly affected by a preferential chain orientation. The $\beta_{2}$ process also appears unchanged regardless of the degree of film extension, which is also consistent with identification as a local process. The $\beta$-process however is almost entirely suppressed. The $\alpha$-process changes considerably, shifting to a higher temperature (113 to $\left.122{ }^{\circ} \mathrm{C}\right)$. The magnitude of the $\alpha$ process also appears to be depressed in the stretched film, displaying a weaker loss modulus (and $\tan \delta$ ) peak.
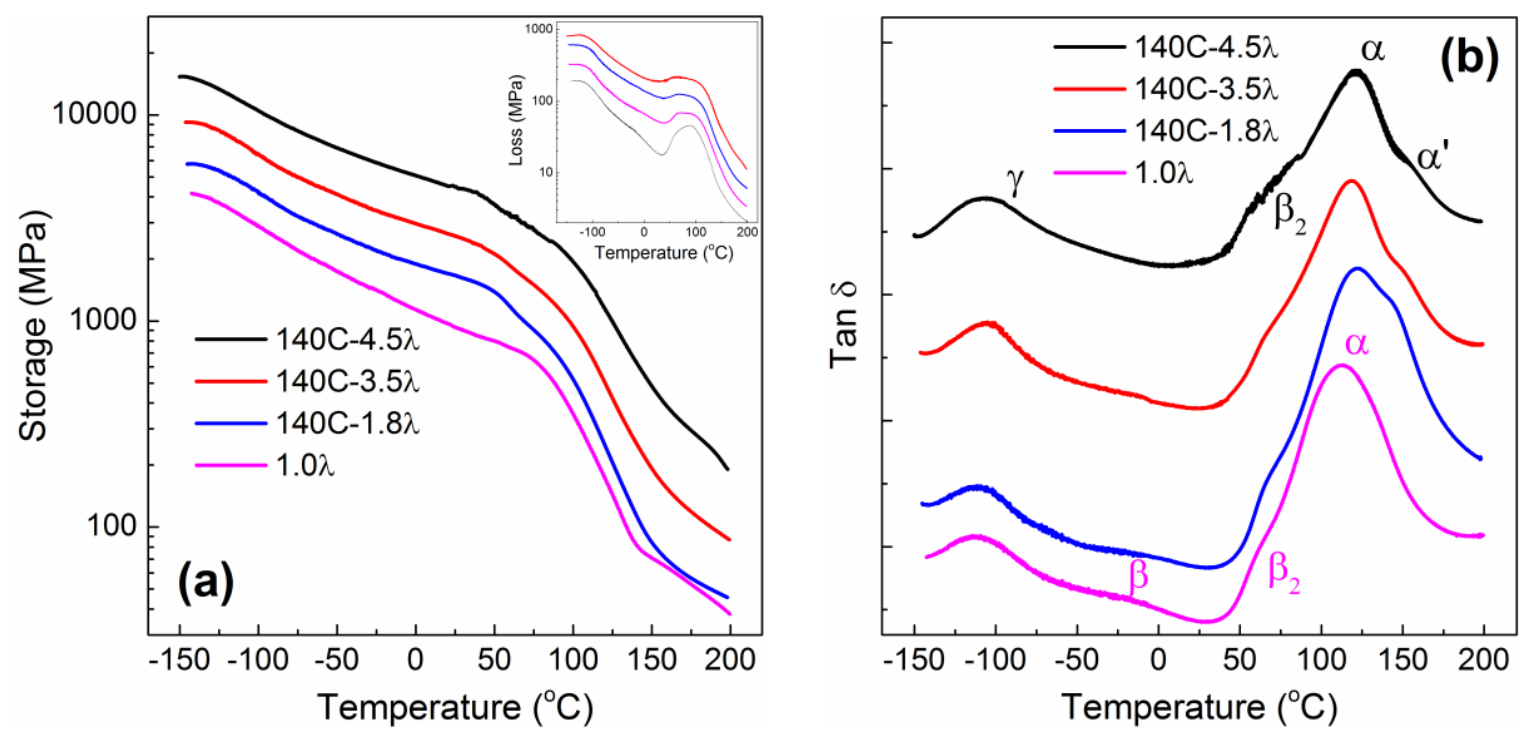
Figure 7. (a) Storage and loss moduli (inset) and (b) $\tan \delta$ of ETFE films undeformed and drawn at $140{ }^{\circ} \mathrm{C}$. The tan $\delta$ plots have been offset for clarity.

A high temperature shoulder also appears off the main $\alpha$-process for films drawn at 140 ${ }^{\circ} \mathrm{C}$, referred as $\alpha$. We assign this to a slow segmental relaxation. The molecular origin may be connected to relaxation of 'rigid amorphous' segments constrained by the crystal interfaces. ${ }^{45-48}$ This rigid non-crystalline fraction presumably formed due to the formation of additional crystal/amorphous interfaces from strain-induced crystallization when drawn at $140{ }^{\circ} \mathrm{C}$. It is also possible that $\alpha^{\prime}$ might be connected to an oriented mesophase, which has been established to restrict segmental motion. ${ }^{35}$ It has also been suggested that a rigid amorphous fraction (RAF) does not require crystal interfaces to form, and the oriented mesophase and RAF may be the same phenomenon. ${ }^{38}$ The orientation and partial ordering of the mesophase restricts motion, and thus oriented amorphous segments require greater thermal energy to achieve segmental relaxation compared to unoriented ones. However, the $\alpha^{\prime}$ process is not visible for films drawn at temperatures below $140{ }^{\circ} \mathrm{C}$, even at the largest draw ratio achieved (Figure 8), reinforcing the idea that the $\alpha^{\prime}$ process is associated with rigid amorphous segments formed due to increased crystallinity of films stretched at $140^{\circ} \mathrm{C}$. 

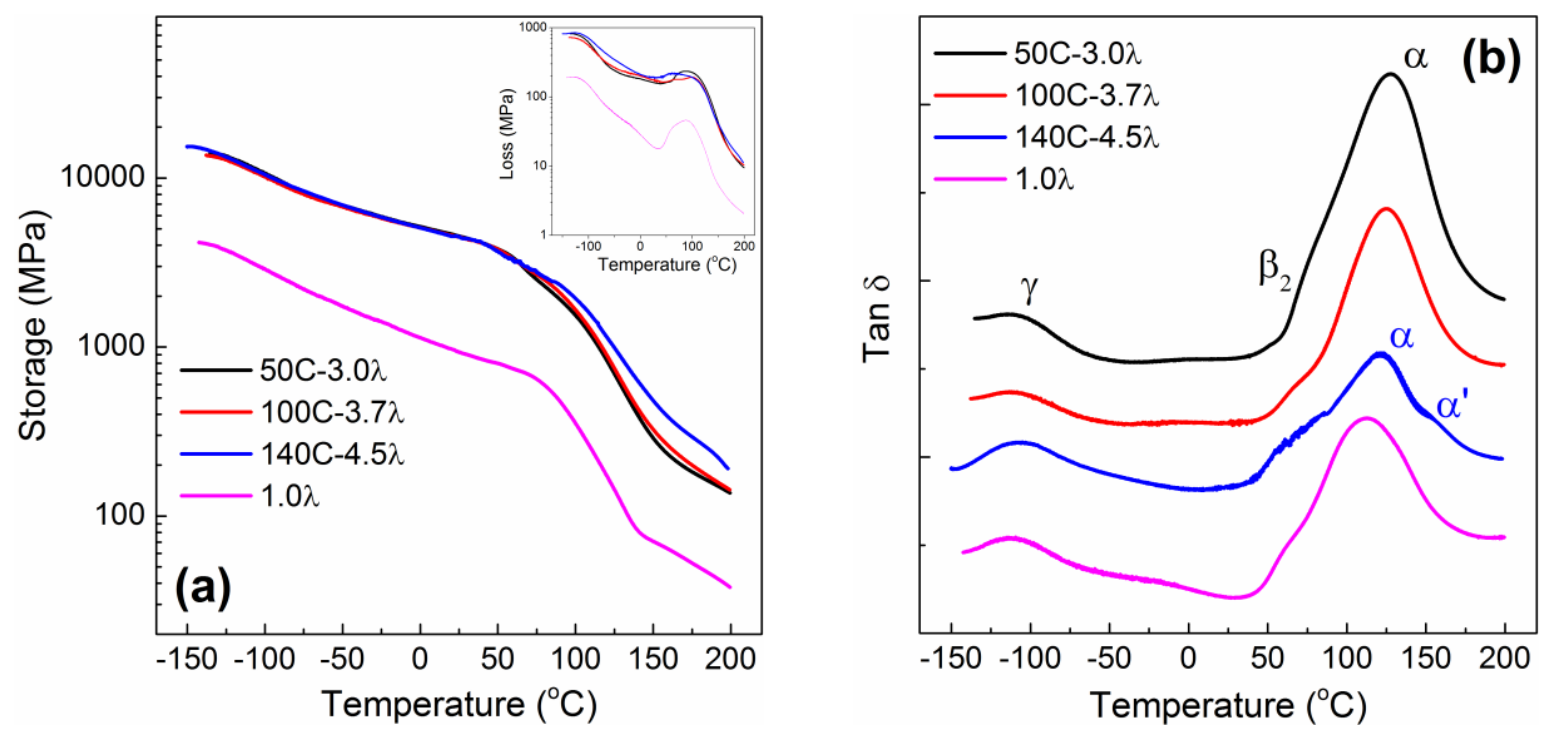

Figure 8. (a) Storage and loss moduli (inset) and (b) tan $\delta$ of selected drawn ETFE films and the undrawn sample. The tan $\delta$ plots have been offset for clarity.

Dielectric relaxation spectroscopy can similarly be used to measure electrical energy storage and loss, allowing interrogation of dipolar relaxations. Figure 9 shows isochronal plots of dielectric loss against temperature, for the unstretched film and for selected films drawn at 50C$3.0 \lambda, 140 \mathrm{C}-2.9 \lambda$, and $140 \mathrm{C}-4.5 \lambda$.

The dielectric spectra of all films share common features - a clear $\gamma$-process at low temperature and an $\alpha$-process at high temperature. The upturn in the loss at temperatures greater than $125{ }^{\circ} \mathrm{C}$ for lower frequency isochrons corresponds to the contribution of conductivity to dielectric loss as charge carriers (most likely residual ionic species) gain sufficient mobility above the $\alpha$-transition. Similar to the DMA findings, the $\gamma$-process does not shift significantly between films tested at a common frequency, but the $\alpha$ relaxation temperature generally increases with film extension ratio. For example, at $10^{4} \mathrm{~Hz}$, the $\gamma$-process resides at $-75^{\circ} \mathrm{C}$ for the unstretched film and $-70{ }^{\circ} \mathrm{C}$ for all three stretched films. However, at this frequency the $\alpha-$ process increases significantly with extension: from $120{ }^{\circ} \mathrm{C}$ for the unstretched film, to $130{ }^{\circ} \mathrm{C}$ 
and $135{ }^{\circ} \mathrm{C}$ for $140 \mathrm{C}-2.9 \lambda$ and $140 \mathrm{C}-4.5 \lambda$, respectively, and $130{ }^{\circ} \mathrm{C}$ for $50 \mathrm{C}-3.0 \lambda$. This increase reflects restriction of chain segmental motion due to the oriented morphology generated by film stretching.
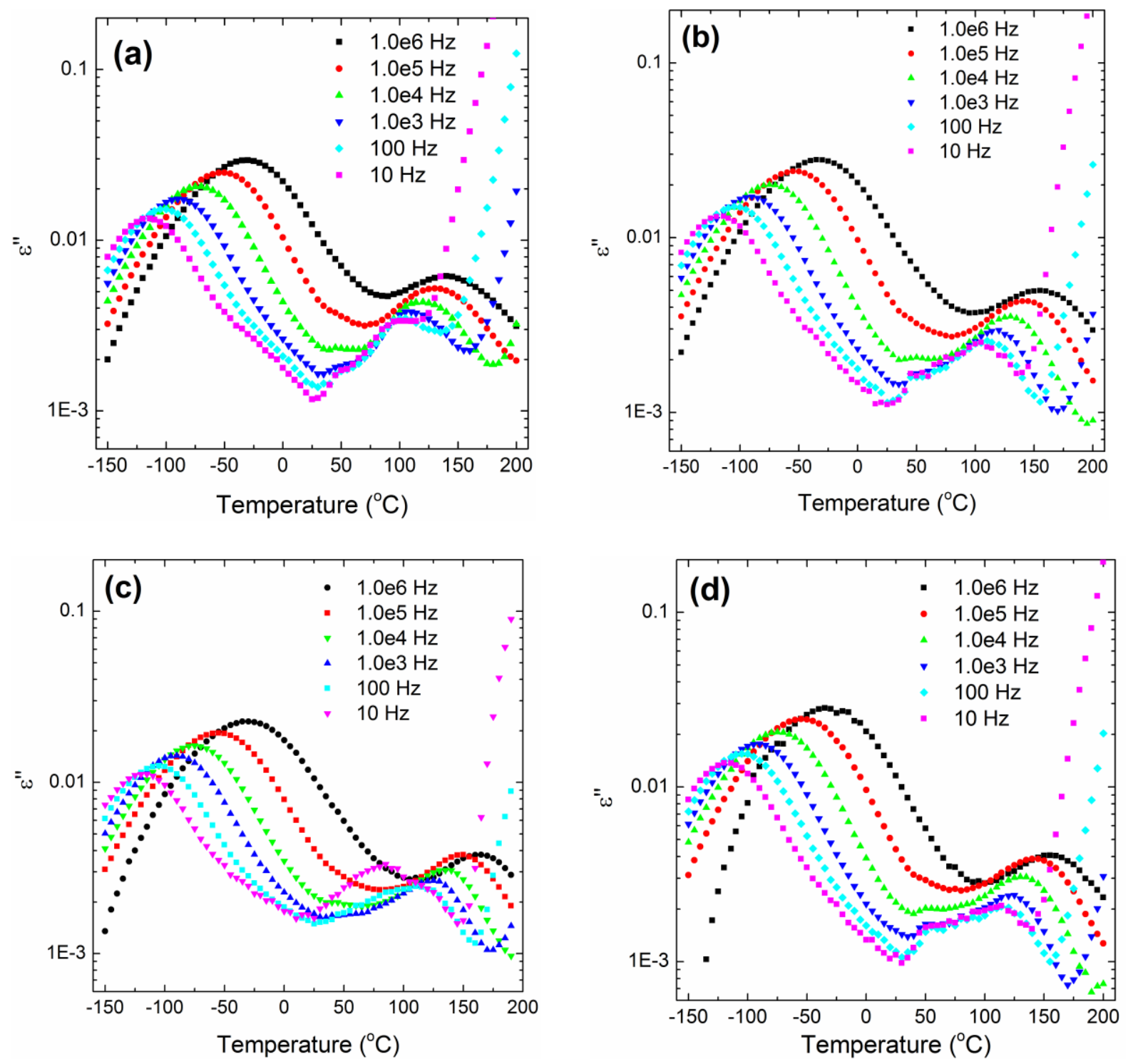

Figure 9. Isochronal plots of dielectric loss factor vs temperature for (a) the unstretched film, (b) $140 \mathrm{C}-2.9 \lambda$, (c) to $140 \mathrm{C}-4.5 \lambda$, and (d) to $50 \mathrm{C}-3.0 \lambda$. 
At high frequencies, subtle relaxations tend to overlap, but may be resolved at lower frequencies. In Figure 9, the $\beta, \beta_{2}$, and $\alpha^{\prime}$-processes are obscured at most frequencies, but can be distinguished at $10 \mathrm{~Hz}$. To make a more clear comparison of these processes between films, isochronal $\tan \delta$ data at $10 \mathrm{~Hz}$ for the unstretched and stretched films were plotted together in Figure 10. At lower frequencies, the contribution from conductivity becomes more significant and overlaps with the $\alpha$ and $\alpha^{\prime}$ relaxations, so it was subtracted from the $\tan \delta$ signal (see Supplementary Data, Figure S5).

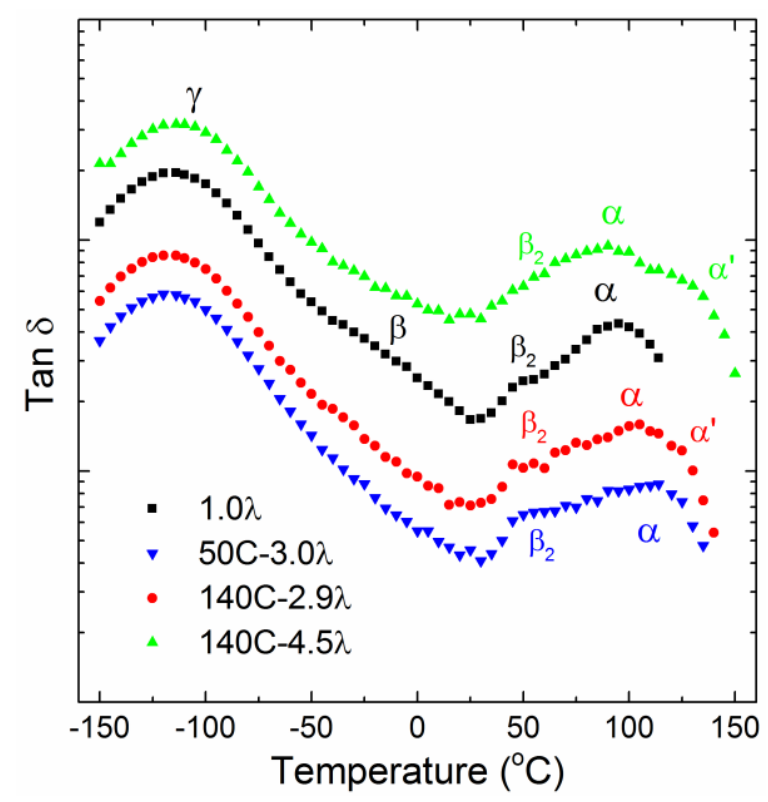

Figure 10. Isochronal plots of dielectric tan $\delta$ vs temperature at $10 \mathrm{~Hz}$ for unstretched and stretched ETFE films (offset for clarity).

From Figure 10, the relaxations follow the same trends as those observed by DMA, as all the mechanical processes are dielectrically active as well. The $\gamma$-process and $\beta_{2}$-process are again independent of the stretching conditions while the nature of the $\alpha$-process changes with the extension ratio, and the $\beta$-process is only observable for the unstretched film. The $\alpha^{\prime}$-process is 
also visible, although it is only clearly seen for the $140 \mathrm{C}-4.5 \lambda$ film. The $140 \mathrm{C}-4.5 \lambda$ film shows the greatest extent of recrystallization into a lamellar structure with smaller period than the original, which should favor the formation of a larger fraction of constrained amorphous segments and therefore increase the magnitude of the $\alpha$ '-process.

The dielectric relaxations were further analyzed by fitting the dielectric loss data to the Havriliak-Negami $(\mathrm{HN})$ equation in order to determine the frequency of maximum loss $\left(f_{\max }\right)$. For the $\alpha$-process, the frequency range of the instrument was insufficient to develop a frequency profile for the dielectric loss for which a good fit of the HN equation could be generated.

For both the $\alpha$ - and $\gamma$-processes of all films, the temperature dependence of dielectric loss follows an Arrhenius form as is typical of local relaxation processes, and the fitting parameters for each relaxation and film condition are summarized in the Supplementary Data section (Table S2). The activation energy changes very little for the $\gamma$-process, but is very dependent on the stretching conditions for the $\alpha^{\prime}$-process, decreasing at conditions which induce the greatest orientation (140C-2.9 $\lambda$ and $140 \mathrm{C}-4.5 \lambda)$.

DRS also provides of measure of ionic conductivity in dielectric polymers (electrical conductivity being negligible at low field strengths). Ionic conductivity results in an immense increase in dielectric loss, and is thus critical to prevent during capacitor operation. Ionic conductivity also provides an indirect measure of amorphous segmental mobility, as conductivity occurs primarily in the amorphous phase and is directly correlated with chain dynamics. ${ }^{49,50}$ The DC conductivity $\left(\sigma_{\mathrm{DC}}\right)$ was determined from the low-frequency plateau of plots of $\sigma^{\prime}$ vs frequency (Supplementary Data, Figure S4). The conductivities were plotted vs. 1000/T, and fit by the VFT equation (Figure 11). The fit parameters are summarized in the Supplementary Data section (Table S3). 


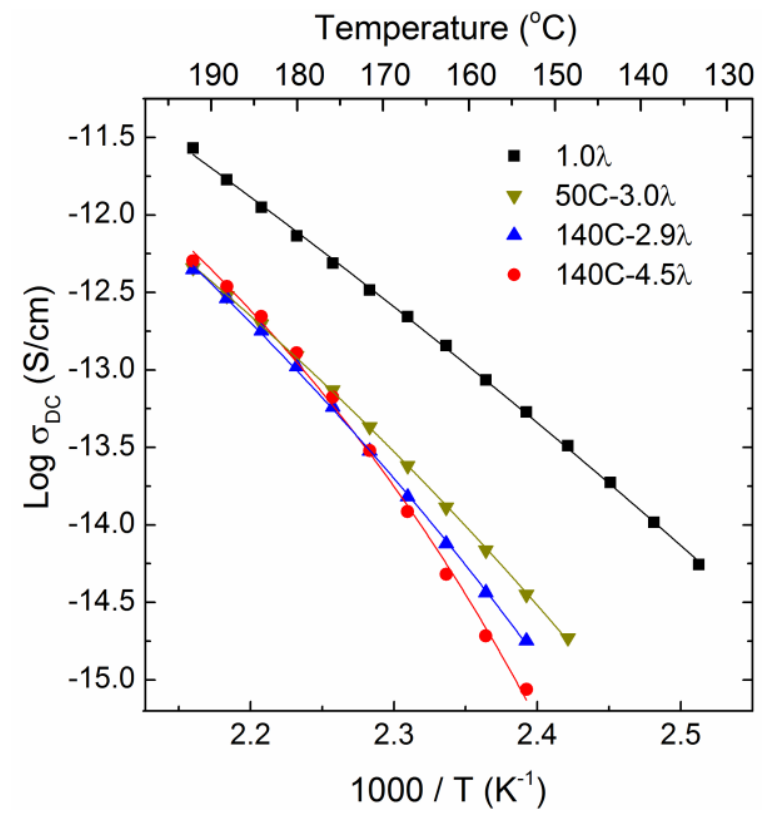

Figure 11. DC conductivity $\left(\sigma_{D C}\right)$ vs inverse temperature for all films.

Comparing each plot, it is clear that orientation greatly decreases the conductivity of the ETFE film. The conductivity is diminished with increasing draw ratio and draw temperature. Increasing draw ratio induces further formation of a rigid amorphous phase, and at higher draw temperatures strain-crystallization is enabled, increasing the RAF. The temperature dependence of $\sigma_{\mathrm{DC}}$ also increases with orientation. The increased dependence, especially at low temperature, may explain why dielectric loss from conduction becomes noticeable at a greater temperature for the stretched films compared to the unstretched films $\left(150{ }^{\circ} \mathrm{C}\right.$ for $140 \mathrm{C}-4.5 \lambda$, compared to 125 ${ }^{\circ} \mathrm{C}$ for $1.0 \lambda$, at $\left.10 \mathrm{~Hz}\right)$.

\section{Conclusions}


ETFE films were drawn to varying extension ratios at temperatures below, near, and above the $\mathrm{T}_{\mathrm{g}}$ of the polymer (i.e., $50{ }^{\circ} \mathrm{C}$, $100{ }^{\circ} \mathrm{C}$, and $140{ }^{\circ} \mathrm{C}$, respectively). All stretching conditions induce a highly oriented morphology, with the highest draw temperatures having the greatest effect. While all resulting morphologies are oriented, there are large differences between films stretched above and below the $\mathrm{T}_{\mathrm{g}}$. Stretching below the $\mathrm{T}_{\mathrm{g}}$ causes the crystal lamellae to split into small fragments which form microfibrils parallel to the stretching direction. There are also signs of extensive microvoid formation, perhaps corresponding to the interstices between microfibrils. When stretching above the $\mathrm{T}_{\mathrm{g}}$, it also appears that the original lamellae are destroyed, but they reorganize at higher extension into new crystalline lamellae with a smaller period than the original. The films with greater orientation degree show an increase in the segmental relaxation temperature due to the restricted freedom of motion imparted by the orientated amorphous region. There also appears to be a second segmental relaxation process at slightly higher temperature than the primary. This secondary relaxation may represent the relaxation of rigid amorphous segments, or an oriented mesophase, both with greater restrictions on motion than the bulk amorphous phase. Lastly, orientation reduces the conductivity from residual ions, delaying the onset of conduction to higher temperature and thus increasing the operating range of potential capacitors constructed with an oriented ETFE dielectric layer.

\section{Acknowledgements:}

The authors gratefully acknowledge the support of the Office of Naval Research, under grant N00014-14-C-0205. We also thank Ms. Nicole Wonderling of the Penn State Materials Research Institute, Dr. Hemant P. Yennawar of the Penn State Huck Institutes for the Life Sciences, and Dr. David Shelleman for technical assistance in film characterization. 


\section{References:}

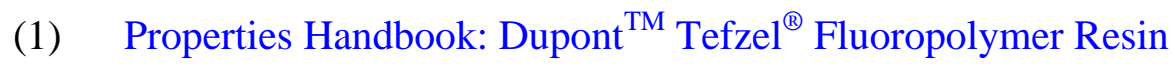

(2) Li, L.; Bowler, N.; Kessler, M. R.; Yoon, S. H. IEEE Trans. Dielectr. Electr. Insul. 2010, 17 (4), 1234-1241.

(3) Reed, C. W.; Cichanowski, S. W. IEEE Trans. Dielectr. Electr. Insul. 1994, 1 (5), 904 922.

(4) Nash, J. L. Polym. Eng. Sci. 1988, 28 (13), 862-870.

(5) Wang, Y.; Zhou, X.; Chen, Q.; Chu, B.; Zhang, Q. IEEE Trans. Dielectr. Electr. Insul. 2010, 17 (4), 1036-1042.

(6) Li, Q.; Han, K.; Gadinski, M. R.; Zhang, G.; Wang, Q. Adv. Mater. 2014, 26 (36), 62446249.

(7) Kim, P.; Doss, N. M.; Tillotson, J. P.; Hotchkiss, P. J.; Pan, M.-J.; Marder, S. R.; Li, J.; Calame, J. P.; Perry, J. W. ACS Nano 2009, 3 (9), 2581-2592.

(8) Shen, Y.; Lin, Y. H.; Li, M.; Nan, C. W. Adv. Mater. 2007, 19 (10), 1418-1422.

(9) Mackey, M.; Hiltner, A.; Baer, E.; Flandin, L.; Wolak, M. a; Shirk, J. S. J. Phys. D. Appl. Phys. 2009, 42 (17), 175304.

(10) Carr, J. M.; MacKey, M.; Flandin, L.; Schuele, D.; Zhu, L.; Baer, E. J. Polym. Sci. Part B Polym. Phys. 2013, 51 (11), 882-896.

(11) Lu, Y.; Claude, J.; Norena-franco, L. E.; Wang, Q. J. Phys. Chem. B 2008, 112, 1041110416.

(12) Chu, B.; Zhou, X.; Ren, K.; Neese, B.; Lin, M.; Wang, Q.; Bauer, F.; Zhang, Q. M. Science (80-. ). 2006, 313 (5785), 334-336.

(13) Dang, Z.-M.; Yuan, J.-K.; Yao, S.-H.; Liao, R.-J. Adv. Mater. 2013, 25 (44), 6334-6365.

(14) Qi, L.; Petersson, L.; Liu, T. J. Int. Counc. Electr. Eng. 2014, 4 (1), 1-6.

(15) Wang, Q.; Zhu, L. J. Polym. Sci. Part B Polym. Phys. 2011, 49 (20), 1421-1429.

(16) Ho, J.; Jow, T. R. Characterization of High Temperature Polymer Thin Films for Power Conditioning Capacitors, Army Research Laboratory: Adelphi, MD 2009; ARL-TR$4880 \mathrm{~F}$

(17) Phongtamrug, S.; Tashiro, K.; Funaki, A.; Arai, K. Polymer 2008, 49 (23), 5072-5083.

(18) Modena, M.; Garbuglio, C.; Ragazzini, M. Polym. Lett. 1972, 10, 153-156.

(19) Arai, K.; Funaki, A.; Phongtamrug, S.; Tashiro, K. Polymer 2010, 51 (21), 4831-4835. 
(20) Zuo, F.; Keum, J. K.; Chen, X.; Hsiao, B. S.; Chen, H.; Lai, S. Y.; Wevers, R.; Li, J. Polymer 2007, 48 (23), 6867-6880.

(21) Williams, G. Adv. Polym. Sci. 1979, 33, 59-92.

(22) Phongtamrug, S.; Tashiro, K.; Funaki, A.; Arai, K.; Aida, S. Polymer 2008, 49 (2), 561569.

(23) Ono, Y.; Kakiage, M.; Yamanobe, T.; Yukawa, Y.; Higuchi, Y.; Kamiya, H.; Arai, K.; Uehara, H. Polymer 2011, 52 (4), 1172-1179.

(24) Uehara, H.; Ono, Y.; Kakiage, M.; Sakamura, T.; Masunaga, H.; Yukawa, Y.; Higuchi, Y.; Kamiya, H.; Yamanobe, T. J. Phys. Chem. B 2015, 119 (11), 4284-4293.

(25) Tanigami, T.; Yamamura, K.; Matsuzawa, S. Polym. Eng. Sci. 1986, 26 (19), 1323-1331.

(26) Tanigami, T.; Yamaura, K.; Matsuzawa, S.; Ishikawa, M.; Mizoguchi, K.; Miyasaka, K. Polymer 1986, 27, 999-1006.

(27) Iuliano, M.; De Rosa, C.; Guerra, G.; Petraccone, V.; Corradini, P. Makromol. Chemie 1989, 190, 827-835.

(28) Pieper, T.; Heise, B.; Wilke, W. Polymer 1989, 30, 1768-1775.

(29) D’Aniello, C.; De Rosa, C.; Guerra, G.; Petraccone, V.; Corradini, P.; Ajroldi, G. Polymer 1995, 36 (5), 967-973.

(30) Wilson, F. C.; Starkweather, H. W. J. Polym. Sci. Part A-2 Polym. Phys. 1973, 11 (5), 919-927.

(31) Tanigami, T.; Yamaura, K.; Matsuzawa, S.; Ishikawa, M.; Mizoguchi, K.; Miyasaka, K. Polymer 1986, 27 (10), 1521-1528.

(32) Gursel, S. A.; Schneider, J.; Ben youcef, H.; Wokaun, A.; Scherer, G. G. J. Appl. Polym. Sci. 2008, 108, 3577-3585.

(33) Lee, B. J.; Parks, D. M.; Ahzi, S. J. Mech. Phys. Solids 1993, 41, 1651.

(34) Dommelen, J. A. W. Van; Parks, D. M.; Boyce, M. C.; Brekelmans, W. A. M.; Baaijens, F. P. T. J. Mech. Phys. Solids 2003, 51, 519-541.

(35) Murthy, N. S.; Bray, R. G.; Correale, S. T.; Moore, R. A. F. Polymer 1995, 36 (20), $3863-$ 3873.

(36) Kwon, Y. K.; Boller, A.; Pyda, M.; Wunderlich, B. Polymer 2000, 41, 6237-6249.

(37) Fu, Y.; Annis, B.; Boller, A.; Jin, Y.; Wunderlich, B. J. Polym. Sci. Part B Polym. Phys. 1994, 32, 2289-2306.

(38) Ma, Q.; Pyda, M.; Mao, B.; Cebe, P. Polymer 2013, 54 (10), 2544-2554.

(39) Ran, S.; Zong, X.; Fang, D.; Hsiao, B. S.; Chu, B.; Ross, R. J. Appl. Crystallogr. 2000, 33 (4), 1031-1036.

(40) Peterlin, A. Colloid Polym. Sci. 1987, 265, 357-382.

(41) Nozue, Y.; Shinohara, Y.; Ogawa, Y.; Sakurai, T.; Hori, H.; Kasahara, T.; Yamaguchi, N.; 
Yagi, N.; Amemiya, Y. Macromolecules 2007, 40, 2036-2045.

(42) Thévenon, A.; Fulchiron, R. Macromol. Mater. Eng. 2014, 299 (2), 165-177.

(43) Liu, L.-Z.; Hsiao, B. S.; Fu, B. X.; Ran, S.; Toki, S.; Chu, B.; Tsou, A. H.; Agarwal, P. K. Macromolecules 2003, 36, 1920-1929.

(44) Jiang, Z.; Tang, Y.; Men, Y.; Enderle, H.; Lilge, D.; Roth, S. V; Gehrke, R.; Rieger, J. Macromolecules 2007, 40, 7263-7269.

(45) Suzukia, H.; Grebowicz, J.; Wunderlich, B. Makromol. Chemie 1985, 186, 1109-1119.

(46) Huo, P.; Cebe, P. Macromolecules 1992, No. 3, 902-909.

(47) Cheng, S. Z. D.; Cao, M.-Y.; Wunderlich, B. Macromolecules 1986, 19, 1868-1876.

(48) Huo, P.; Cebe, P. Colloid Polym. Sci. 1992, 270 (9), 840-852.

(49) Lee, S.; Schomer, M.; Peng, H.; Page, K. A.; Wilms, D.; Frey, H.; Soles, C. L.; Yoon, D. Y. Chem. Mater. 2011, 23, 2685-2688.

(50) Bruce, P. G.; Vincent, C. A. J. Chem. Soc. Faraday Trans 1993, 89 (17), 3187-3203.

\section{Appendix A. Supplementary Data}

Supplementary data is available at: 'hyperlink' 
Induce orientation by mechanical drawing

Randomly oriented crystals
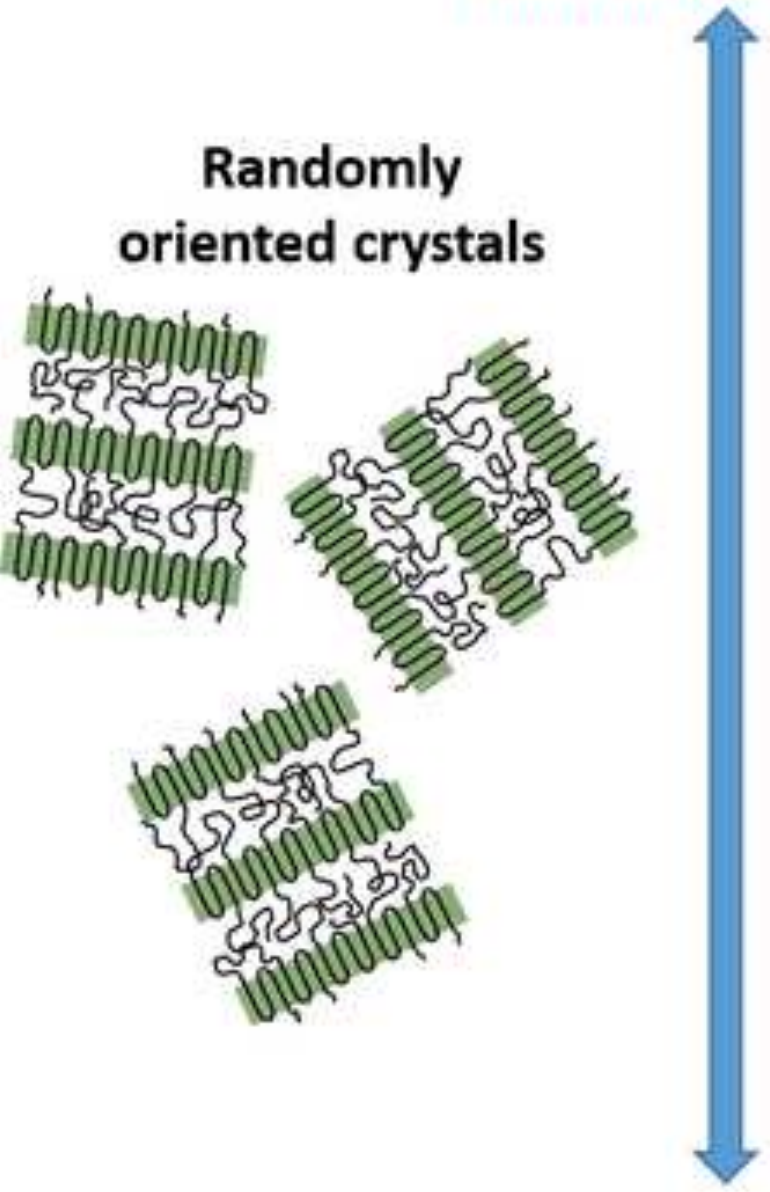
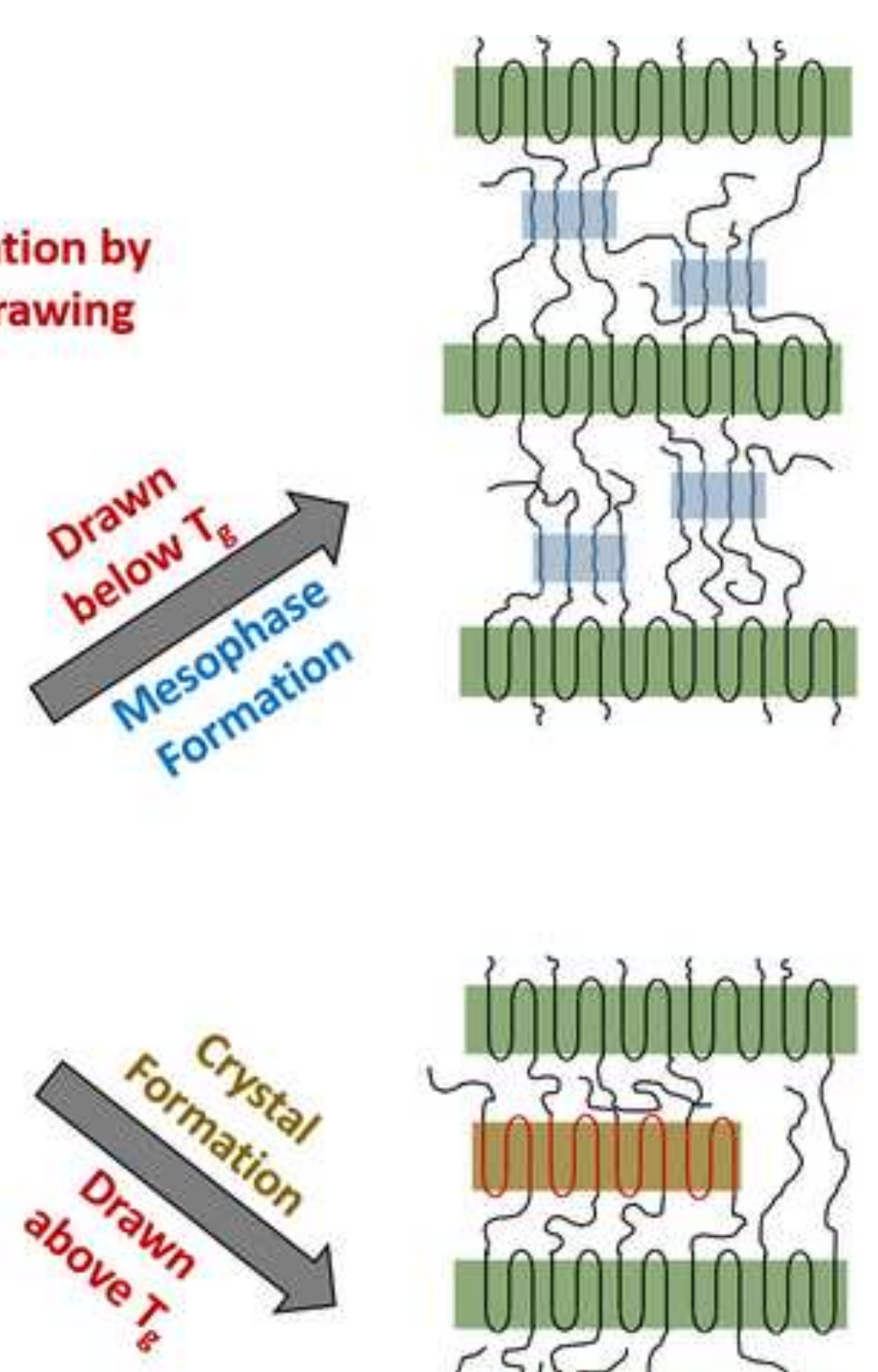

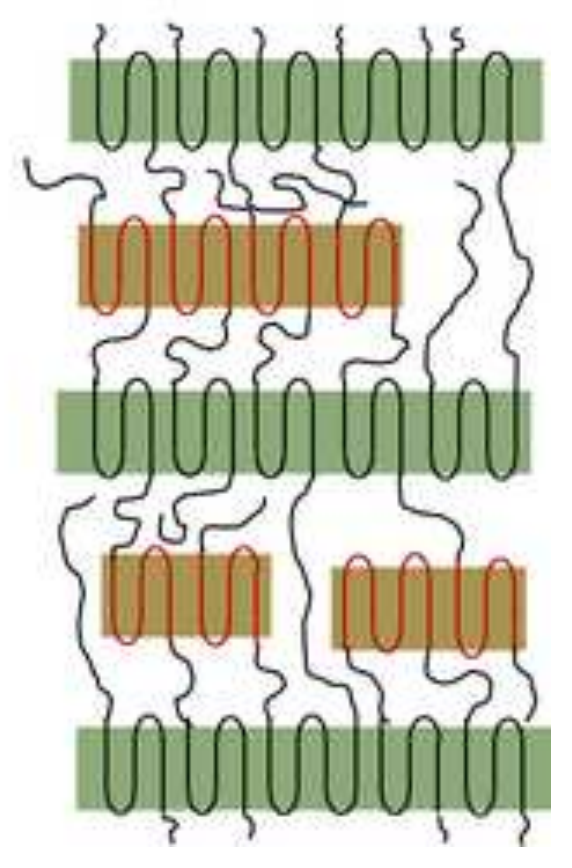

